\title{
Interaction between an Eco-Spiral Bolt and Crushed Rock in a Borehole Evaluated by Pull-Out Testing
}

\author{
Seong-Seung Kang, ${ }^{1}$ Atsuo Hirata, ${ }^{2}$ Bo-An Jang, ${ }^{3}$ Yong-Seok Seo, ${ }^{4}$ and Daehyeon Kim ${ }^{5}$ \\ ${ }^{1}$ Department of Energy and Resources Engineering, Chosun University, Gwangju 61452, Republic of Korea \\ ${ }^{2} R S$ Technology Co., Ltd. and Sojo University, Kumamoto 862-0941, Japan \\ ${ }^{3}$ Department of Geophysics, Kangwon National University, Chuncheon 24341, Republic of Korea \\ ${ }^{4}$ Department of Earth and Environment Sciences, Chungbuk National University, Cheongju 28644, Republic of Korea \\ ${ }^{5}$ Department of Civil Engineering, Chosun University, Gwangju 61452, Republic of Korea
}

Correspondence should be addressed to Daehyeon Kim; dkimgeo@chosun.ac.kr

Received 8 June 2017; Accepted 17 July 2017; Published 29 August 2017

Academic Editor: Luigi Nicolais

Copyright (c) 2017 Seong-Seung Kang et al. This is an open access article distributed under the Creative Commons Attribution License, which permits unrestricted use, distribution, and reproduction in any medium, provided the original work is properly cited.

\begin{abstract}
The interactions between an eco-spiral bolt and crushed rocks in a borehole were evaluated by pull-out testing in a laboratory and numerical analysis. The porosity of the crushed rock surrounding the bolt depended on the size of the eco-spiral bolt and affected the eco-spiral bolt's axial resistance force. The axial resistance force and the porosity of the crushed rocks in the borehole showed an inverse relationship. The porosity was also related to the size of the eco-spiral bolt. The maximum principal stress between the bolt and the rock was related to the porosity of the crushed rock and the size difference between the eco-spiral bolt and the borehole. At low porosity the experimental and numerical analyses show similar relationships between the axial resistance force and the displacement. However, at high porosity, the numerical results deviated greatly from the experimental observation. The initial agreement is attributed to the state of residual resistance after the maximum axial resistance force, and the latter divergence was due to the decreasing axial resistance force owing to slippage.
\end{abstract}

\section{Introduction}

Civil and mining engineering employs various devices for support and reinforcement [1-7]. Examples include ground anchors, which are mainly used for ground reinforcement, and rock and cable bolts that reinforce rock [8,9]. Supports of various types can restrict the subsequent deformation of the geostructures due to further excavation [10-13].

Eco-spiral bolts have been developed to stabilize geostructures and constructions such as foundation, tunnel, and slope. They are manufactured by repeatedly twisting a steel sheet bar [14-16] and are suitable for use in both soft ground and rock mass due to the high axial resistance force that the ground applies to the bolt. Eco-spiral bolts can be directly installed in soft ground using only a twisting force without drilling. Therefore, the geostructure between the ground and the bolt is not disturbed and installation is quick. Eco-spiral bolts can be installed in hard rock mass in the same way as rock and cable bolts.
This study aims to define the interactions between the eco-spiral bolt and the crushed rock in a borehole by pullout testing using laboratory test and numerical analysis. For this purpose, the effect of porosity with respect to the different sizes of the eco-spiral bolt and the crushed rock was firstly clarified by laboratory pull-out testing. Secondly, the relationship between the axial resistance force and the displacement was evaluated depending on the different sizes of the eco-spiral bolt and the crushed rock in a borehole. Finally, the maximum principal stress between the eco-spiral bolt and the crushed rock was also evaluated by numerical analysis.

\section{Experiments and Properties of Materials}

2.1. Pull-Out Test. Various eco-spiral bolts exist for a range of purposes. Figures 1(a) and 1(b) show a steel sheet bar before twisting and the resulting eco-spiral bolt. The twisting angle $\theta$ is $45^{\circ}$ from the central line of the eco-spiral bolt 


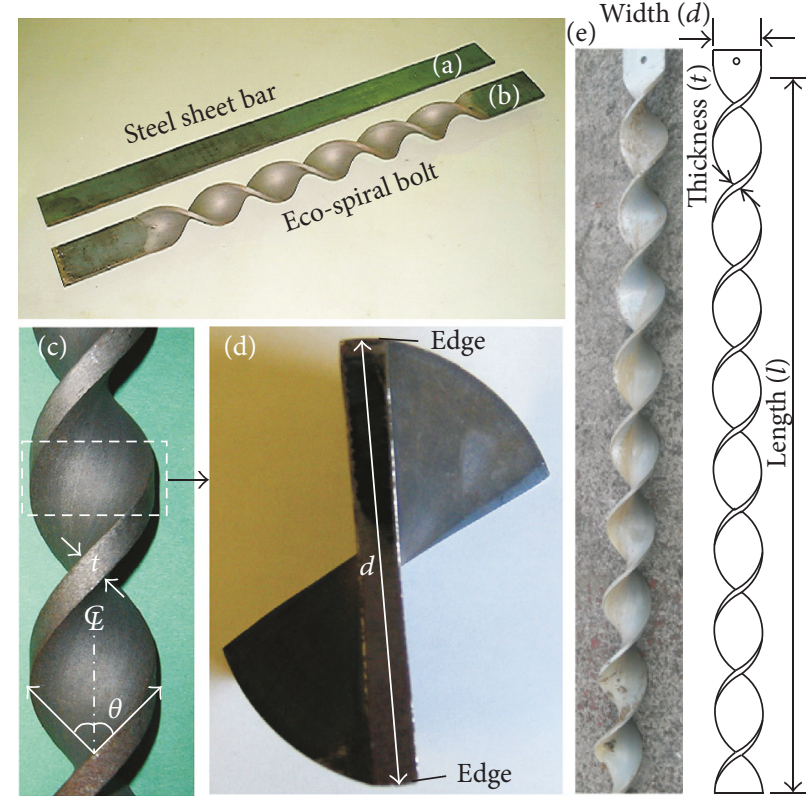

Figure 1: Photographs of (a) a steel bar, (b) an eco-spiral bolt, (c) the twisting angle of the bolt, (d) a section view of the bolt, and (e) each designation of the bolt.

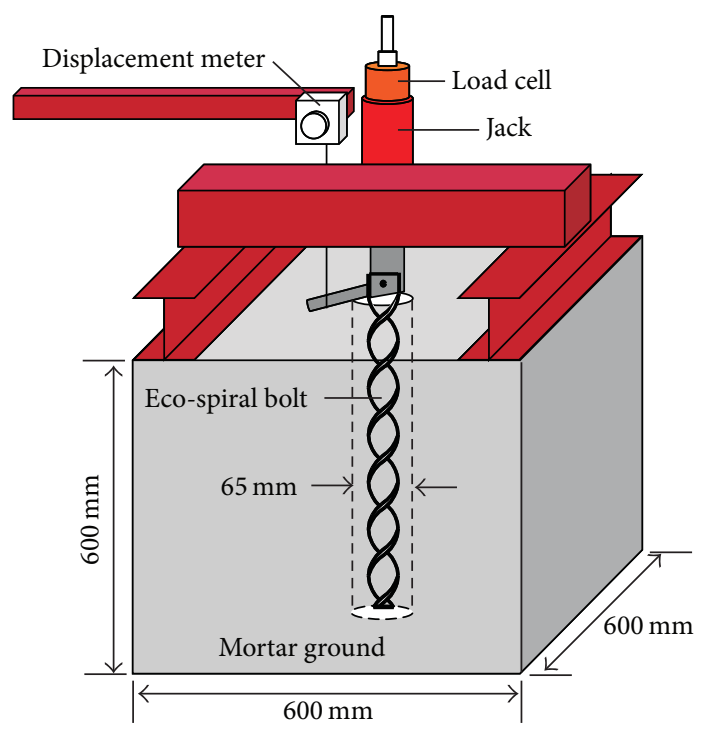

FIGURE 2: Schematic diagram of equipment for pull-out testing.

(Figure 1(c)). Figure 1(d) represents the bolt's section. Each designation of the bolt with the thickness $t$, the width $d$, and the length $l$ is shown in Figure 1(e). The equipment for pullout testing is outlined in Figure 2. The mortar ground model was a cube with $600 \mathrm{~mm}$ edge length. A borehole of $65 \mathrm{~mm}$ diameter was drilled into the center of the model. Crushed rock was packed into the empty space around an eco-spiral bolt installed in the borehole. To examine the optimal size of the eco-spiral bolt to be used as support for the borehole, the pull-out tests employed three types of eco-spiral bolt. They were all $6 \mathrm{~mm}$ thick and $600 \mathrm{~mm}$ long, but their widths $d$ varied: $32 \mathrm{~mm}$ (SB-1), $38 \mathrm{~mm}$ (SB-2), and $50 \mathrm{~mm}$ (SB-3). In addition, the optimum particle size of the crushed rock filler for the borehole was assessed by pull-out tests performed using three different rock size ranges. The displacement and load were measured using a wire-type displacement meter with the maximum length of $500 \mathrm{~mm}$ and a hollow cylindrical load cell with a capacity of $200 \mathrm{kN}$. All data were recorded using a data logger.

2.2. Crushed Rock. Type 2505 crushed rock (density $2.097 \mathrm{~g} /$ $\mathrm{cm}^{3}$ ), as classified by Japanese Industrial Standards (JIS) A5005-1988, was packed into the boreholes; this is commonly used in concrete in Japan (Figure 3). Figure 4(a) shows the 


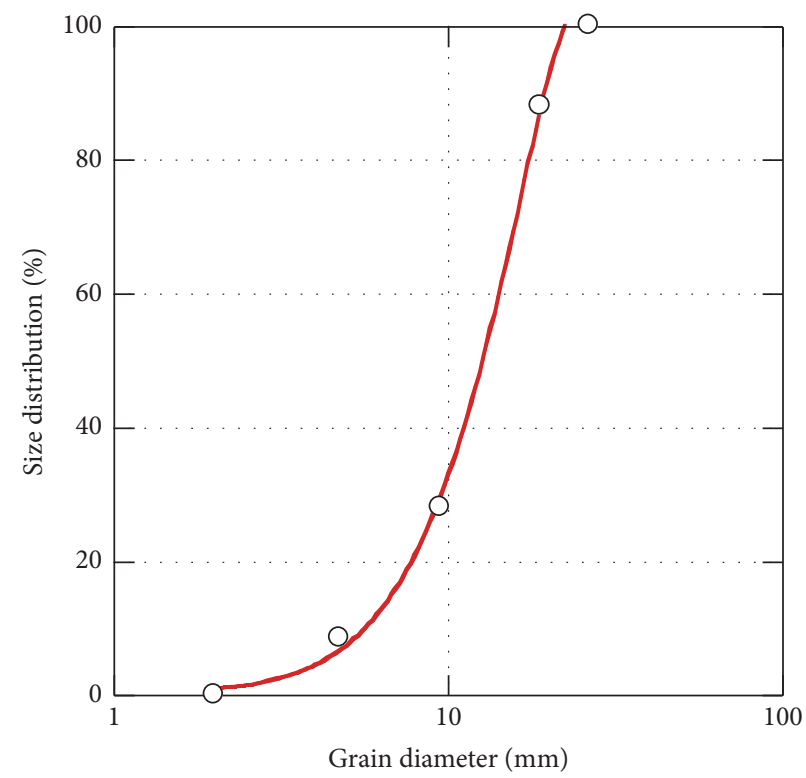

FIGURE 3: Cumulative size curve for crushed rock particles (2505 type, JIS A5005-1988, used for concrete in Japan).

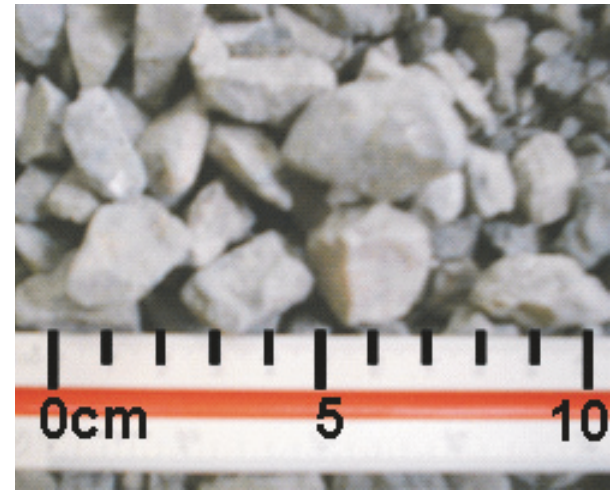

(a)

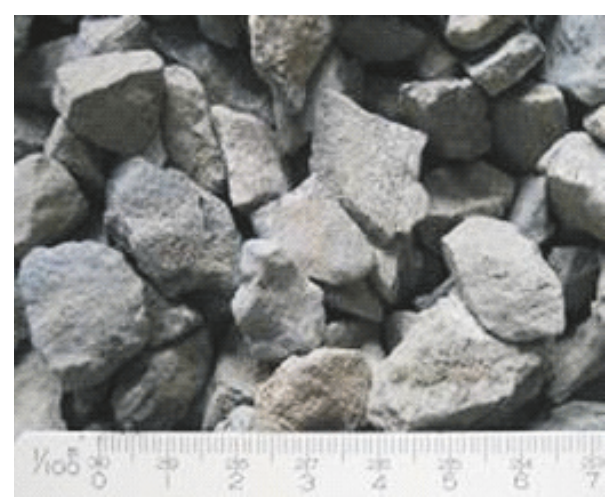

(c) CR-2

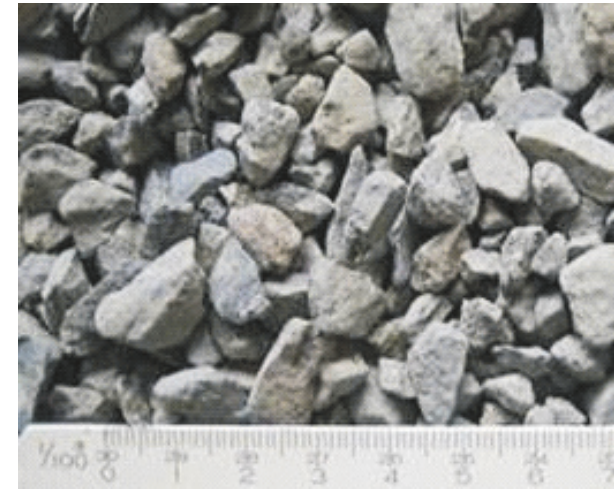

(b) CR-1

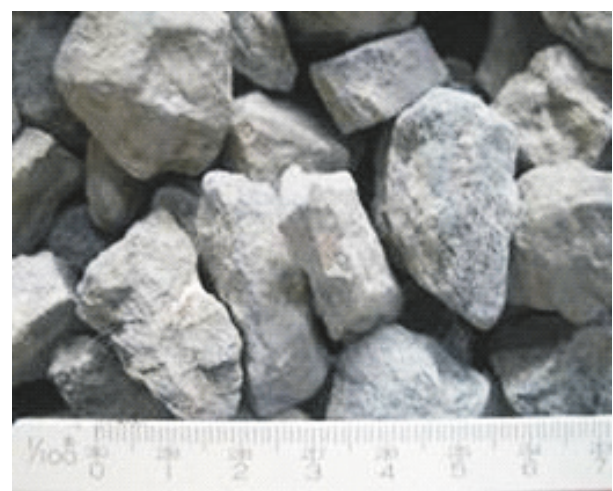

(d) CR-3

Figure 4: Classification of crushed rocks by diameter: (a) mixed sizes of 2-26.5 mm, (b) 4.75-9.75 mm (CR-1), (c) 9.75-14.9 mm (CR-2), and (d) $>14.9 \mathrm{~mm}(\mathrm{CR}-3)$. 


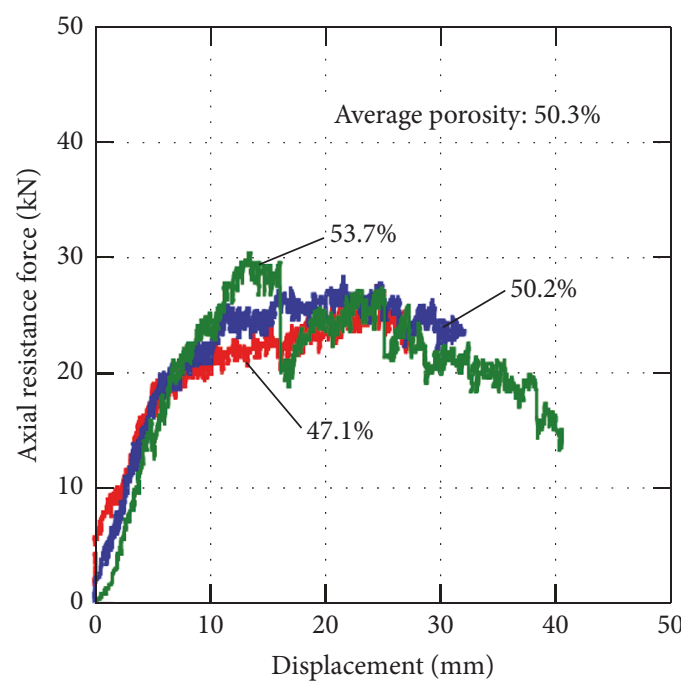

(a) SB-1

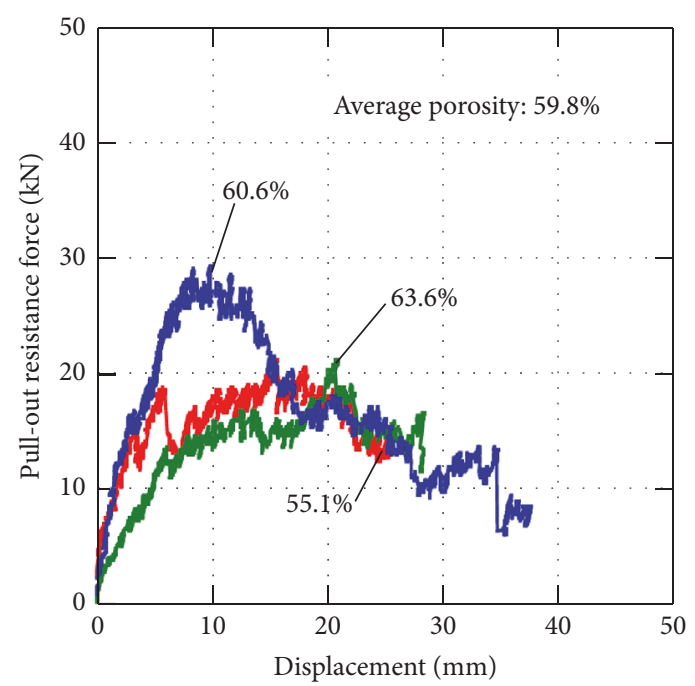

(b) SB-2

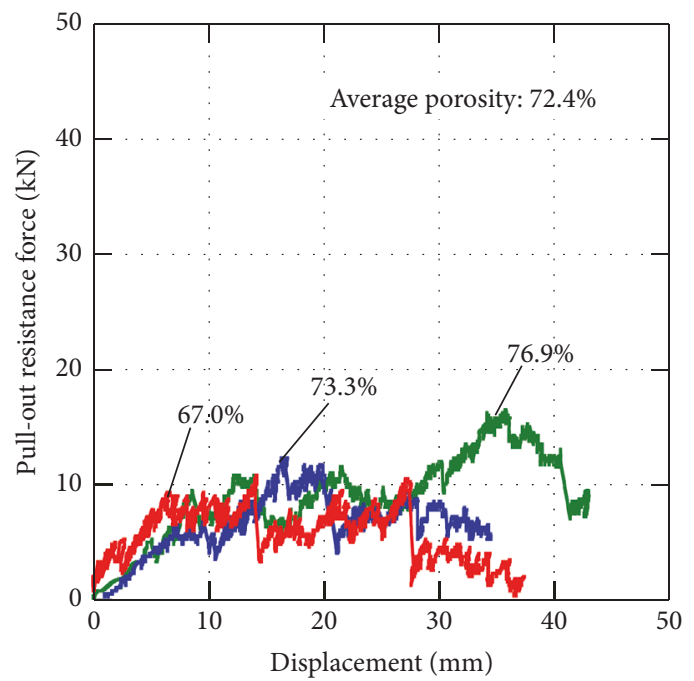

(c) SB-3

FIGURE 5: Relationship between axial resistance force and displacement for various sizes of eco-spiral bolt with widths of (a) $32 \mathrm{~mm}$ (SB-1), (b) $38 \mathrm{~mm}$ (SB-2), and $50 \mathrm{~mm}$ (SB-3). Each eco-spiral bolt is $9 \mathrm{~mm}$ thick and $600 \mathrm{~mm}$ long.

originally mixed particle sizes of diameter $2.0-26.5 \mathrm{~mm}$. Figures $4(\mathrm{~b})-4(\mathrm{~d})$ represent the crushed rock sorted by particle sizes, with diameters of 4.75-9.75 mm (CR-1), 9.75-14.90 mm (CR-2), and $>14.90 \mathrm{~mm}$ (CR-3), respectively. The particles are mainly distributed in the diameter range of $10.0-20.0 \mathrm{~mm}$ (Figure 3). The porosity of the crushed rock packed into a borehole is very important factor because it is closely related to the axial resistance force generated by pull-out testing. In general, the porosity depends on several factors: packing density, particle size distribution, particle shapes, and cementing. In this study, the measuring procedures of porosity were conducted based on guidance from the ISRM [17].

\section{Results of Pull-Out Test}

3.1. Axial Resistance versus Displacement for Different EcoSpiral Bolt. Figure 5 presents the relationship between the axial resistance force and the displacement of the different eco-spiral bolts in the composite crushed rock with the mixed particle sizes of diameter 2.0-26.5 mm during pull-out testing. The average porosity was $50.3 \%$ for SB-1 (Figure 5(a)), $59.8 \%$ for SB-2 (Figure 5(b)), and 72.4\% for SB-3 (Figure 5(c)). The test was carried out three times under the same conditions. In all cases, the axial resistance force increased to the maximum at a displacement range of $10-20 \mathrm{~mm}$ and then gradually decreased. While the width of SB-1 bolt was 1.2 times and 1.6 times smaller than that of SB-2 and SB- 3 bolts, its average maximum axial resistance force was $23 \mathrm{kN}$ over 1.3 times and 2.6 times that of SB-2 $(18 \mathrm{kN})$ and SB-3 $(9 \mathrm{kN})$. An interesting feature of the SB-3 profile is that the axial resistance force due to the displacement of the bolt abruptly decreased and then increased. This is attributed to the bolt slipping in the crushed rock, because the rock surrounding SB-3 was more porous than that around SB-1. As the pullout load increased, the displacement increased, and the axial 


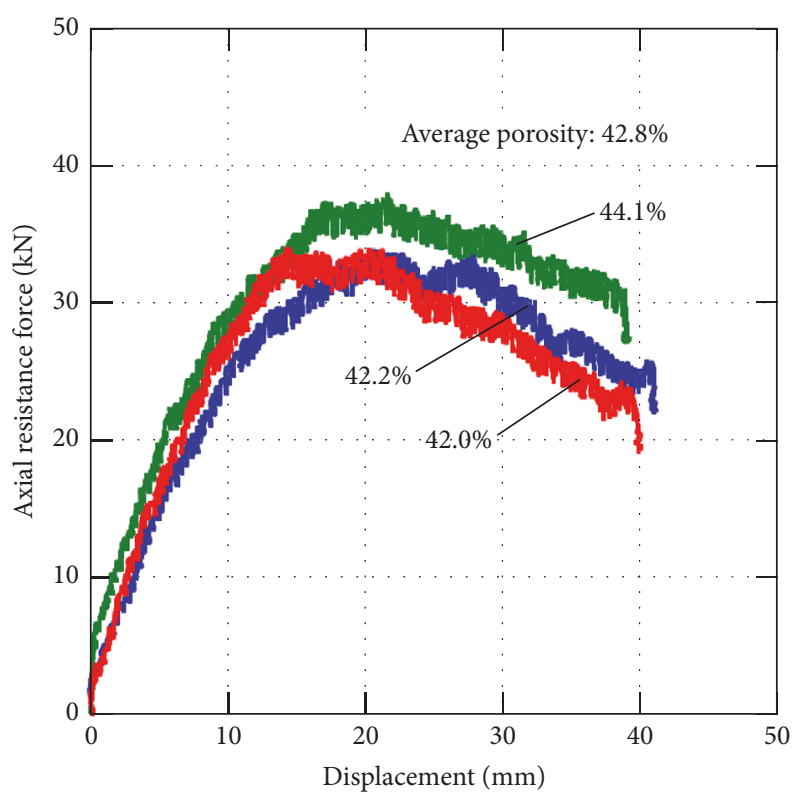

(a) CR-1

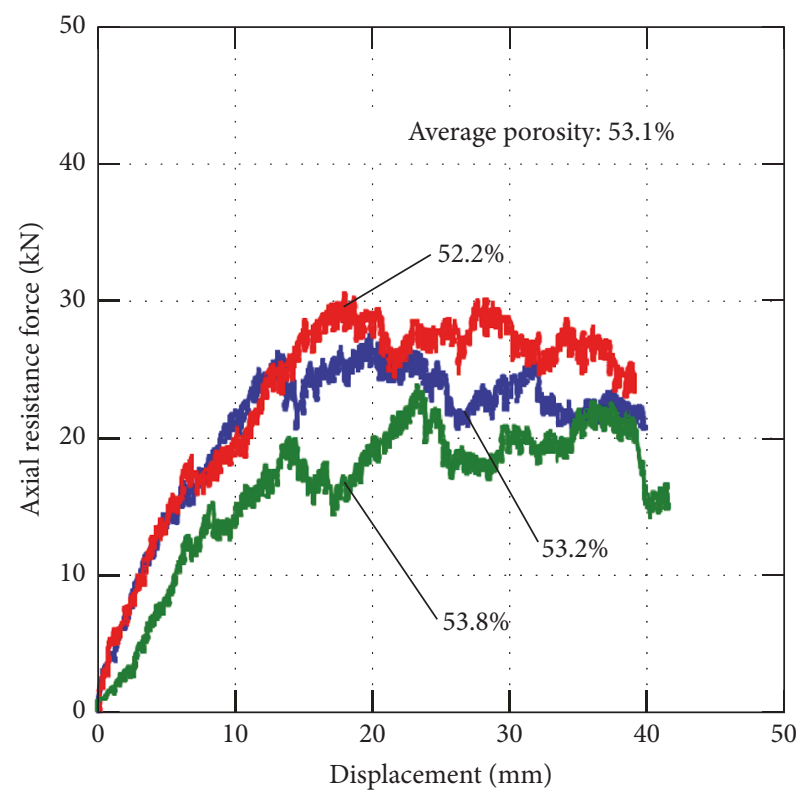

(b) CR-2

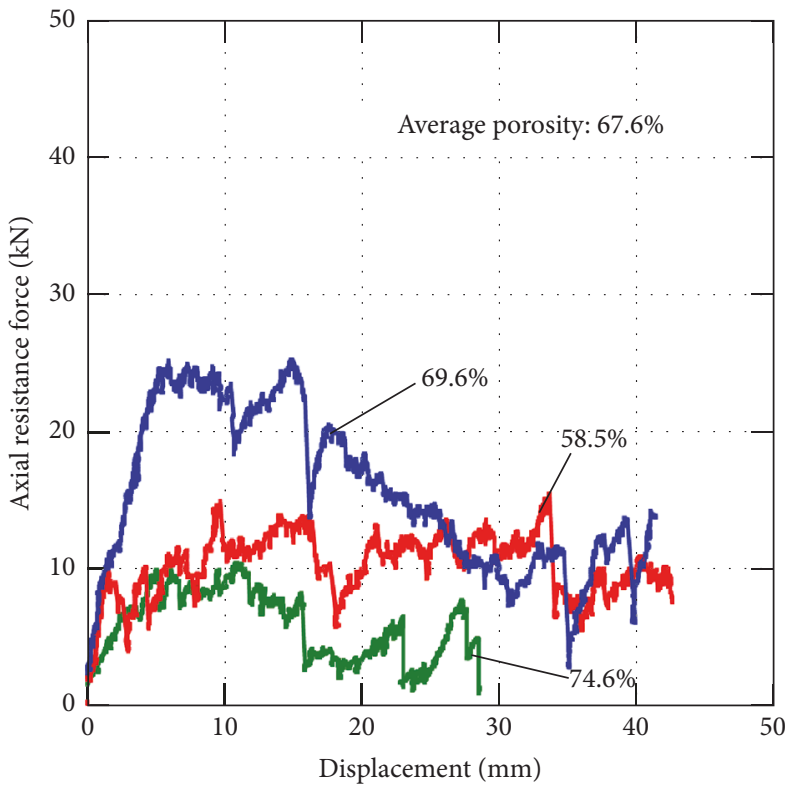

(c) CR-3

FIGURE 6: Relationship between axial resistance force and displacement for various sizes of crushed rock particles with diameters of (a) 4.75-9.75 mm (CR-1), (b) 9.75-14.9 mm (CR-2), and (c) >14.9 mm (CR-3) using SB-1 bolt ( $d=32 \mathrm{~mm})$.

resistance force increased due to the rearranging of the crushed rock structure. The axial resistance force of SB-2 was intermediate between those of SB-1 and SB-3, and slippage occurred, similarly to SB-3. Given the different porosity in each case, the results indicate that the porosity of the crushed rock greatly affected the axial resistance force of the bolt and subsequently its support stability.
3.2. Axial Resistance versus Displacement for Different Crushed Rock. Figure 6 shows the relationship between the axial resistance force and the displacement of the three different sizes of the crushed rock, CR-1, CR-2, and CR-3 during pullout testing. The average porosity was $42.8 \%$ for CR-1 (Figure 6(a)), 53.1\% for CR-2 (Figure 6(b)), and 67.6\% for CR-3 (Figure 6(c)). The axial resistance force peaked in each case 


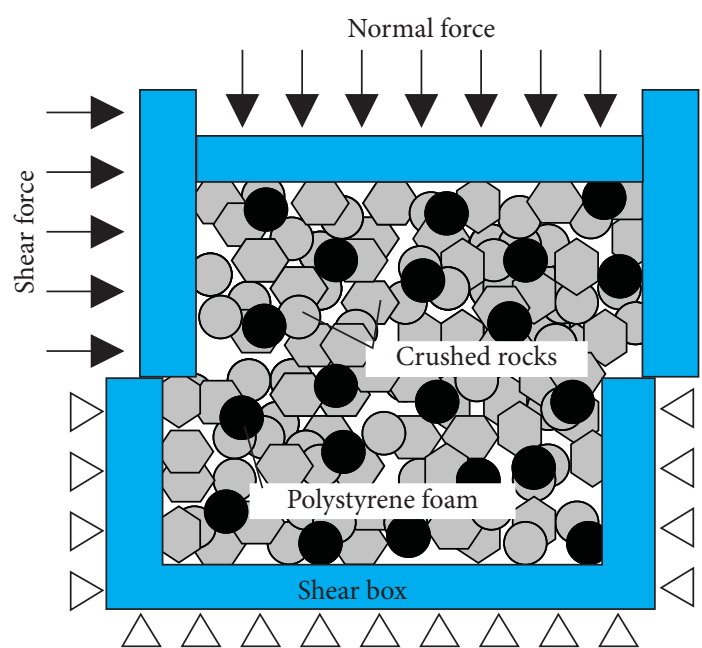

FIgURE 7: Schematic diagram showing the shear testing of crushed rock.

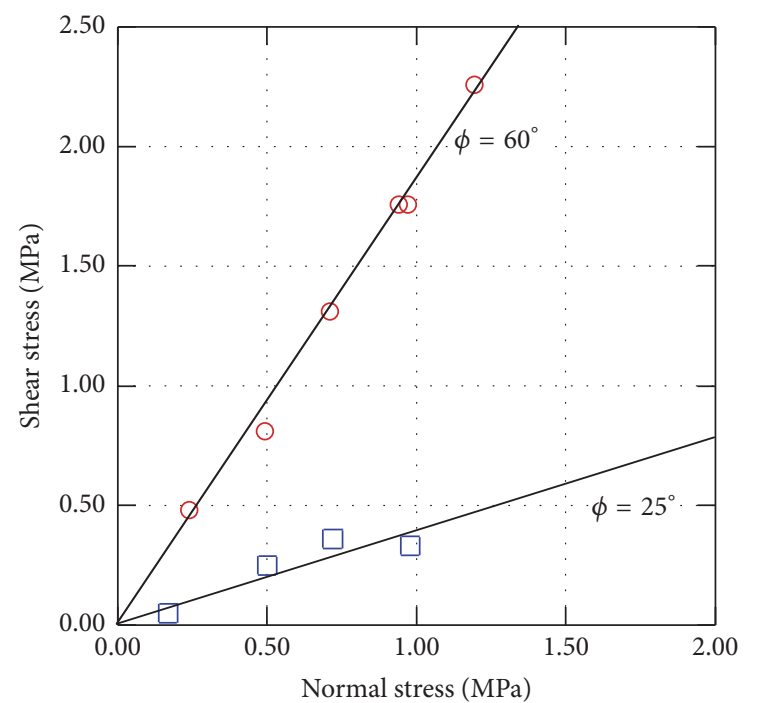

○ Porosity $48 \%$

$\square$ Porosity $70 \%$

FIGURE 8: The relationship between shear stress and normal stress obtained by shear testing ( $\phi$ : internal friction angle).

within the displacement range of $10-20 \mathrm{~mm}$; it then decreased gradually, while the deformation tended to increase. When the particle size of the crushed rock is increased, its porosity also increased, which destabilized the slip frequency of the eco-spiral bolt.

\section{Numerical Analysis}

4.1. Shear Test. To confirm the internal friction angle of the crushed rock, a shear test was performed on the unsorted crushed rock (i.e., Figure 4(a)). Figure 7 outlines the test setup. The porosity was adjusted using a mixture of crushed rock and polystyrene foam to fill the space between the eco-spiral bolt and the borehole. The result of shear tests is shown in Figure 8. It indicates that the crushed rock had a porosity of
$48 \%$ being able to correspond with Figure 6(a) and 70\% being able to correspond with Figure 6(c). The internal friction angle was $60^{\circ}$ at a porosity of $48 \%$ and $25^{\circ}$ at a porosity of $70 \%$.

4.2. Numerical Models for FLAC-3D. The conditions under which the eco-spiral bolt can settle in the borehole were investigated from numerical modeling using the FLAC-3D based on the finite different method [18, 19]. Models of SB-1 and SB-3 for numerical analysis are demonstrated in Figure 9 and are labeled SBN-1 and SBN-3, respectively. Each model is represented by the shear strength expressed in terms of cohesion $c$, internal friction angle $\phi$, and the elastic deformation (in terms of Young's modulus $E$ and Poisson's ratio $v$ ) according to Mohr-Coulomb theory. When the elastic deformation exceeds the shear strength, it becomes a complete plastic body. The eco-spiral bolt is treated as a rigid body. In addition, it is assumed that there is no slippage between the eco-spiral bolt and the crushed rock. Both models employed $c=6 \mathrm{MPa}$ and $\phi=56^{\circ}$ for the ground and $c=0 \mathrm{MPa}$ for the crushed rock; the crushed rock in model SBN-1 had $\phi=40^{\circ}$ obtained from SB-1 of porosity $50.3 \%$ and $60^{\circ}$ from porosity $48 \%$, while it had $\phi=15^{\circ}$ obtained from SB-3 of porosity $72.4 \%$ and $25^{\circ}$ from porosity $70 \%$ in model SBN-3. The Young's moduli of the ground and the eco-spiral bolt were $20 \mathrm{GPa}$ and $74 \mathrm{GPa}$, respectively.

4.3. Maximum Principal Stress. Figure 10 shows the change in the maximum principal stress at the point of $195 \mathrm{~mm}$ from the top of the model and the distribution of the maximum principal stress when the displacements are $0.07 \mathrm{~mm}$ (initial loading), $8.20 \mathrm{~mm}$ (middle loading), and $27.00 \mathrm{~mm}$ (late loading). A positive value indicates compressive stress. The central rectangle in the figure represents the eco-spiral bolt, and the dashed line is the borehole. During the initial loading, no change in the maximum principal stress was observed in the SBN-1 and SBN-3 models. However, during the middle loading in both cases, the eco-spiral bolt compresses the ground in the radial direction. At this time, the magnitude of the maximum principal stress is $23.30 \mathrm{kN}$ for SBN-1 and $12.25 \mathrm{kN}$ for SBN-3: the maximum principal stress of SBN-1 is clearly larger and occupies a wider area than in the case of SBN-3. The maximum principal stress during the late loading is similar to that during the middle loading and is concentrated at both edges of the eco-spiral bolt. These results mean that the maximum principal stress is related to the porosity of the crushed rock and the difference in size between the eco-spiral bolt and the borehole.

4.4. Comparison of Experimental and Numerical Results. Figure 11 compares the experimental and numerical results for the relationship between the axial resistance force and displacement. The numerical results for model SBN-1 with an internal friction angle of $40^{\circ}$ agree well with the experimental values up to a displacement of $20 \mathrm{~mm}$. On the other hand, the numerical results with an internal friction angle of $60^{\circ}$ do not agree with the experimental results. The axial resistance force in both the experimental and numerical results peaked in the displacement of 20-30 $\mathrm{mm}$ and then gradually decreased. 


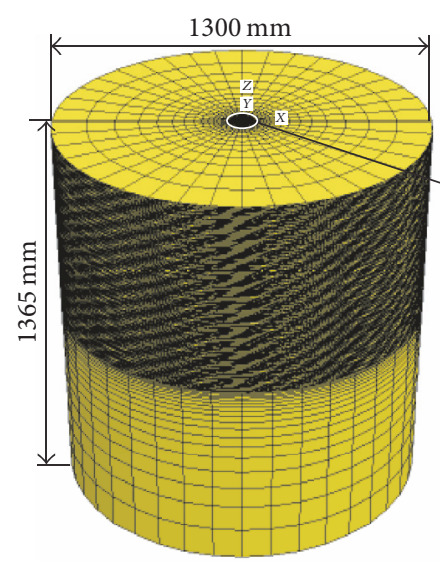

(a)

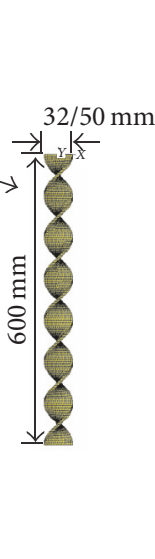

\section{k}

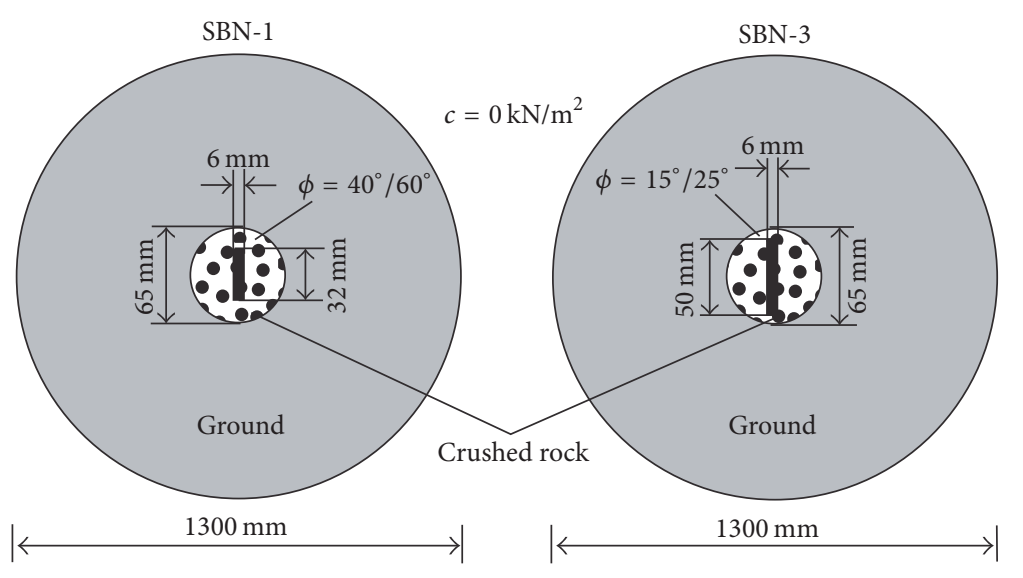

(b)

FIgUre 9: (a) Model and (b) sections of SBN-1 and SBN-3 for numerical analysis ( $c$ : cohesion, $\phi$ : internal friction angle).
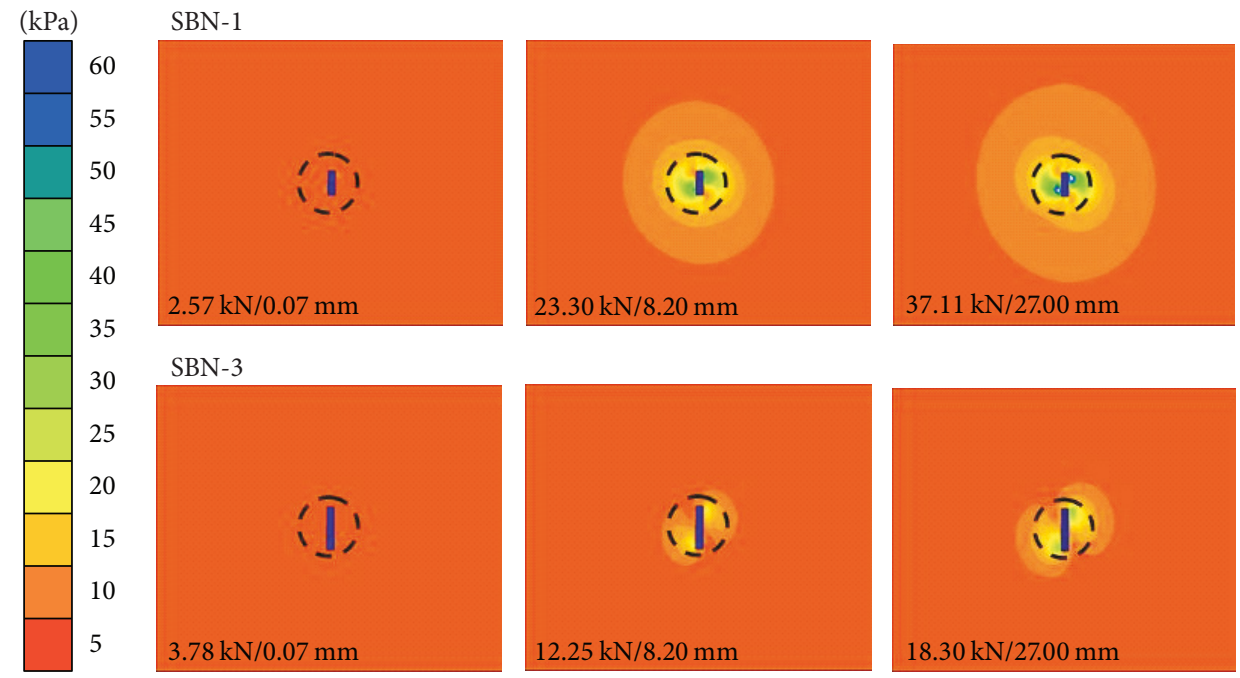

SBN-3
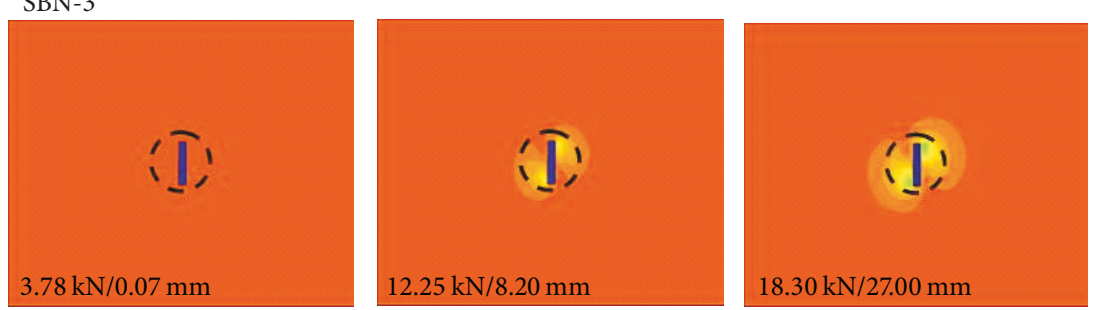

FIGURE 10: Variation in maximum principal stress at $195 \mathrm{~mm}$ from the top of the model in SBN-1 and SBN-3 when the displacement is $0.07 \mathrm{~mm}$ (initial loading), $8.20 \mathrm{~mm}$ (middle loading), and $27.00 \mathrm{~mm}$ (late loading).

The axial resistance force-displacement behavior matched well until the force reached its maximum, but not necessarily after that. The numerical results for SBN-3 with internal friction angles of either $15^{\circ}$ or $25^{\circ}$ do not agree with the experimental results. The large slippage that occurred with displacement in the experimental results is an especially notable porosity difference between the crushed rock and the eco-spiral bolt and was an important factor reducing the axial resistance force. Therefore, for the eco-spiral bolt to be well settled among the crushed rock particles in a borehole, it is important that the frictional force between the crushed rock and the eco-spiral bolt can be effectively maintained.

\section{Conclusions}

Pull-out testing in a laboratory was carried out to evaluate the effect of the porosity of the crushed rock surrounding an ecospiral bolt in a borehole. Numerical analyses were also run, and the relationship between the axial resistance force and the bolt's displacement was compared with the experimental results.

The porosity of the crushed rock surrounding the ecospiral bolt depended on both their sizes. For a given particle size, the porosity increased as the size of the eco-spiral bolt increased, while for a given eco-spiral bolt size the porosity increased as the size of the crushed rock particles increased. Therefore, the porosity showed a proportional relationship with the sizes of both the crushed rock particles and the ecospiral bolt.

When the eco-spiral bolt is much narrower than the borehole, the crushed rock was packed tightly and the porosity was low, leading to sufficient axial resistance force to hold the bolt in place. If the contact between the crushed rock and the eco-spiral bolt is unstable due to insufficient filling with the crushed rock, the eco-spiral bolt can slip. Therefore, it is important to determine the appropriate sizes of the ecospiral bolt and the particle sizes of crushed rock to ensure sufficient axial resistance force, because slipping is a major 


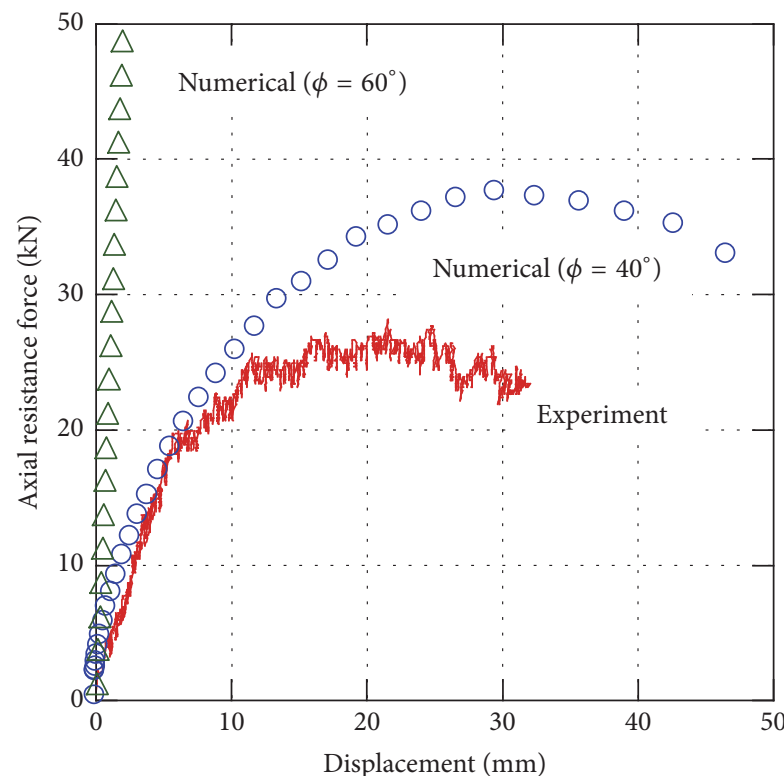

(a)

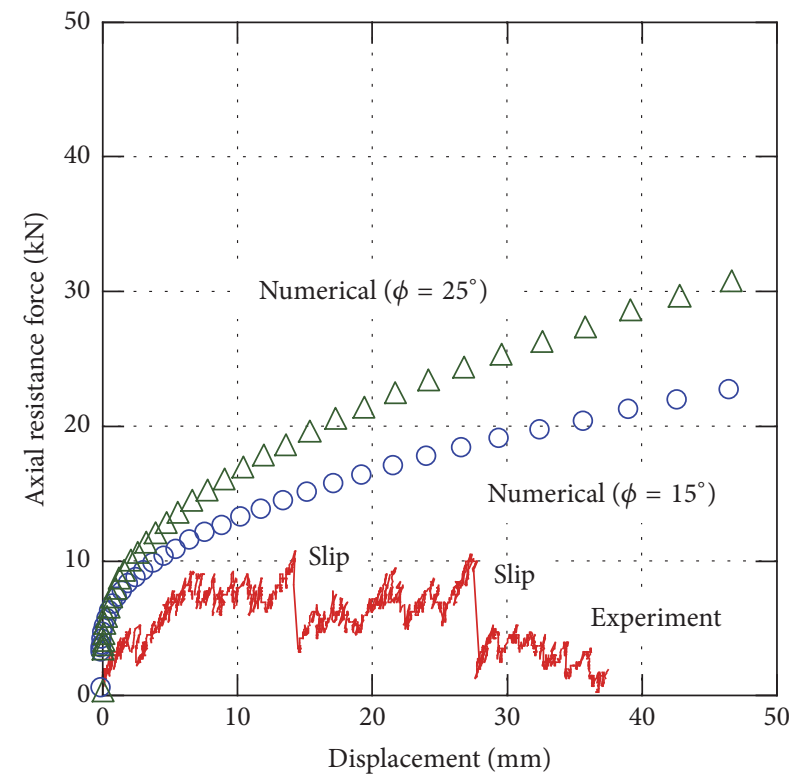

(b)

FIGURE 11: Comparison of the relationship between axial resistance force and displacement as experimentally measured and numerically calculated for cases (a) SBN-1 and (b) SBN-3 ( $\phi$ : internal friction angle).

factor reducing the axial resistance force. After use, eco-spiral bolts can be recovered and reused. Because grouting is not required, they are also advantageous for stabilizing dangerous site.

\section{Conflicts of Interest}

The authors declare that they have no conflicts of interest.

\section{Acknowledgments}

This research was supported by a grant from Construction Technology Research Program funded by Ministry of Land, Infrastructure and Transport of Korean Government (no. 15SCIP-C069312-03).

\section{References}

[1] B. Indraratna and P. K. Kaiser, "Design for grouted rock bolts based on the convergence control method," International Journal of Rock Mechanics and Mining Sciences and, vol. 27, no. 4, pp. 269-281, 1990.

[2] P. K. Kaiser, S. Yazici, and J. Nosé, "Effect of stress change on the bond strength of fully grouted cables," International Journal of Rock Mechanics and Mining Sciences and, vol. 29, no. 3, pp. 293-306, 1992.

[3] S. Yazici and P. K. Kaizer, "Bond strength grouted cable bolts," International Journal of Rock Mechanics and Mining Sciences \& Geomechanics Abstracts, vol. 29, pp. 279-292, 1992.

[4] A. J. Hyett, W. F. Bawden, and R. D. Reichert, "The effect of rock mass confinement on the bond strength of fully grouted cable bolts," International Journal of Rock Mechanics and Mining Sciences and, vol. 29, no. 5, pp. 503-524, 1992.
[5] A. J. Hyett, W. F. Bawden, G. R. Macsporran, and M. Moosavi, "A constitutive law for bond failure of fully-grouted cable bolts using a modified hoek cell," International Journal of Rock Mechanics and Mining Sciences and, vol. 32, no. 1, pp. 11-36, 1995.

[6] D. D. Tannant, R. K. Brummer, and X. Yi, "Rockbolt behavior under dynamic loading: Field tests and modeling," International Journal of Rock Mechanics and Mining Sciences \& Geomechanics Abstracts, vol. 32, pp. 537-550, 1995.

[7] Y. Obara, Y. Maeno, and S. S. Kang, "Constitutive law of fullygrouted cable bolts and its application to support design," Journal of the Mining and Materials Processing Institute of Japan, vol. 126, pp. 432-439, 2010, in English with Japanese abstract.

[8] B. H. Brady and E. T. Brown, Rock mechanics for underground mining, George Allen \& Unwin, 1985.

[9] J. A. Franklin and M. B. Dusseault, Rock Engineering, McGrawHill, 1989.

[10] C. R. Windsor and A. G. Thompson, Rock reinforcement Technology, testing, design and evaluation. Comprehensive Rock Engineering: Principles, Practice and Projects, Oxford: Pergamon Press, 1993.

[11] C. R. Windsor, "Rock reinforcement systems," International Journal of Rock Mechanics and Mining Sciences, vol. 34, no. 6, pp. 919-951, 1997.

[12] F. Ito, F. Nakahara, R. Kawano, S.-S. Kang, and Y. Obara, "Visualization of failure in a pull-out test of cable bolts using X-ray CT," Construction and Building Materials, vol. 15, no. 5-6, pp. 263-270, 2001.

[13] Y. Maeno, R. Kawano, S. S. Kang, and Y. Obara, "Mechanical behavior of cable bolts in laboratory pull-out test," Journal of the Mining and Materials Processing Institute of Japan, vol. 124, pp. 756-764, 2008, in English with Japanese abstract.

[14] A. Hirata, S. Kokaji, M. Fujita, A. Akamine, and T. Goto, "Dilation stress in borehole induced by a spiral anchor," in Proceedings of the 3rd International Symposium on Rock Stress, pp. 499-505, Balkema, Rotterdam, 2003. 
[15] A. Hirata, S. Kokaji, S. S. Kang, and G. Goto, "Study on the estimation of the axial resistance of spiral bar based on interaction with ground," Journal of the Mining and Materials Processing Institute of Japan, vol. 121, pp. 370-377, 2005, in English with Japanese abstract.

[16] S. S. Kang, A. Hirata, and Y. Obara, "A method for estimating of axial resistance of spiral bar developed as a new earth support system," Korean Society of Civil Engineers, vol. 25, pp. 387-394, 2005, in English with Korean abstract.

[17] ISRM, "Rock characterization testing and monitering, ISRM suggested methods," in The Commission on Testing Methods, International Society for Rock Mechanics, E. T. Brown, Ed., pp. 1-21, Pergamon Press, 1981.

[18] ITASCA, Theory and background for FLAC3D, Version 2.0, Itasca Consulting Group Inc., Minnesota, 2002.

[19] P. Cundall and M. Board, "A microcomputer program for modeling large-strain plasticity problems," in Proceedings of the 6th International Conference on Numerical Methods in Geomechanics, pp. 2101-2108, Balkema, Rotterdam, 1988. 

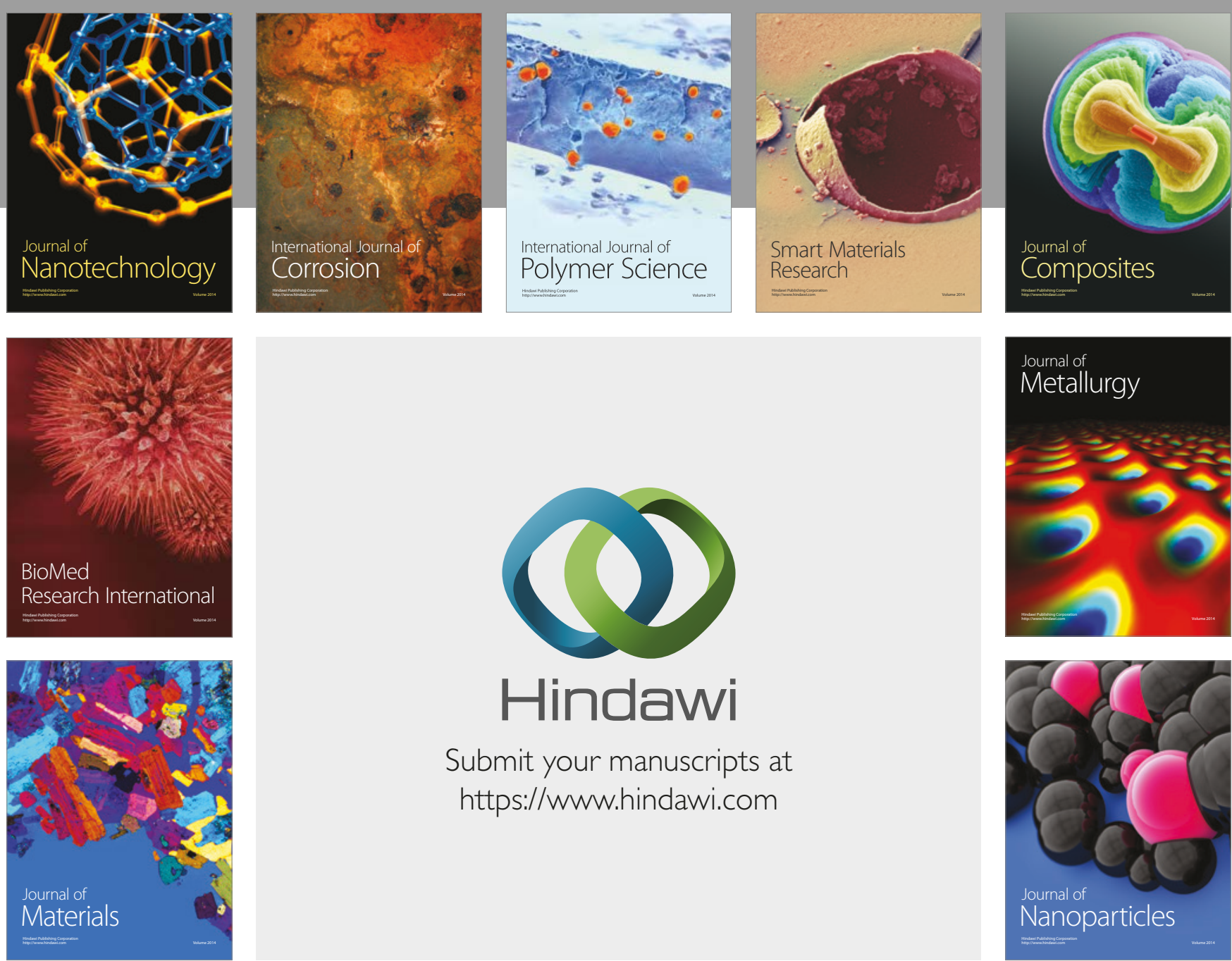

\section{Hindawi}

Submit your manuscripts at

https://www.hindawi.com
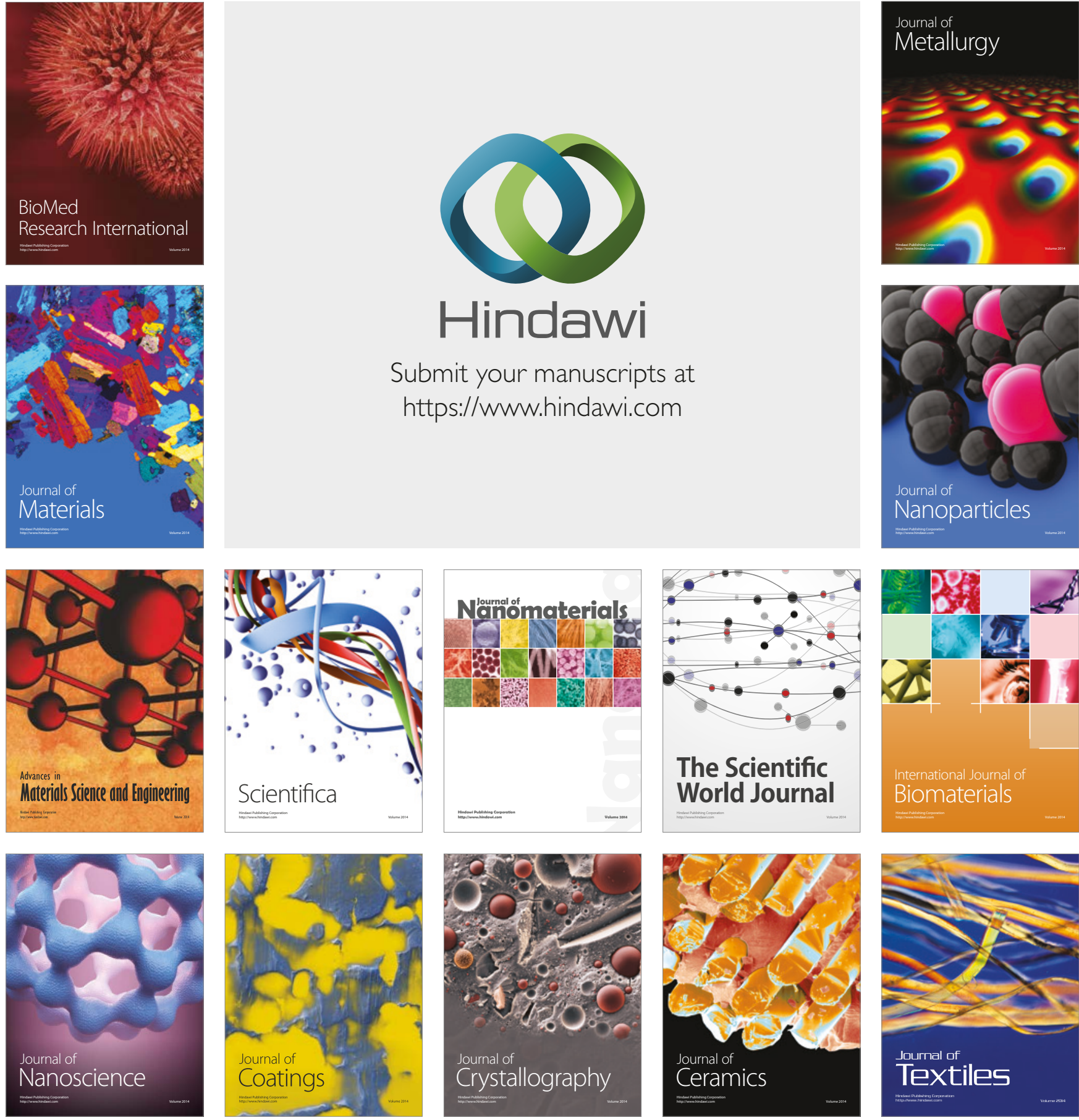

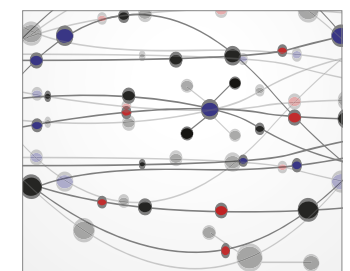

The Scientific World Journal
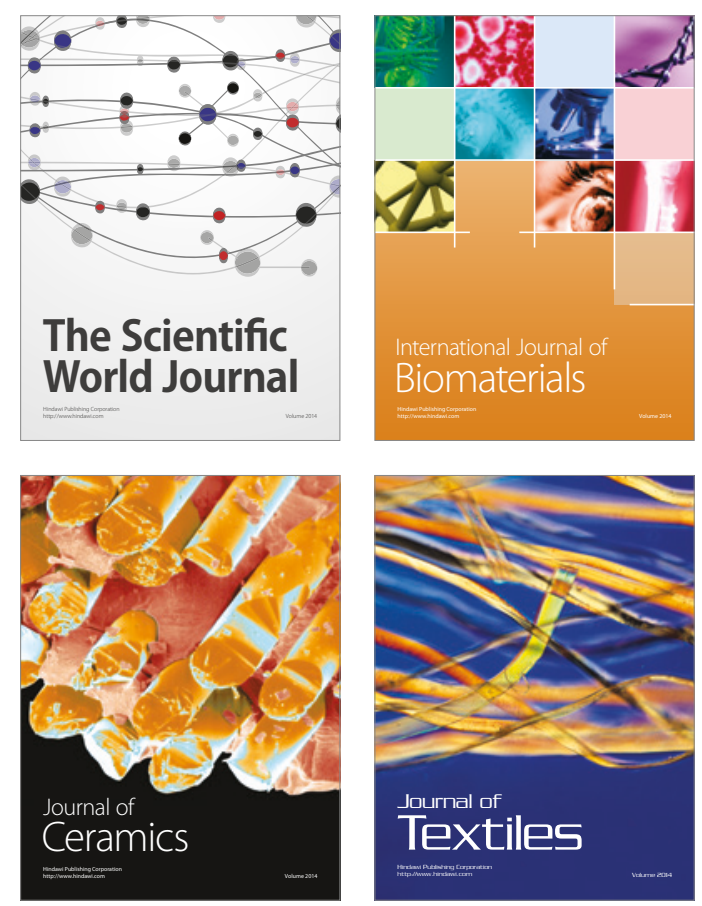